\title{
Atuação do Psicólogo Escolar e Educacional no ensino superior: reflexões sobre práticas
}

\author{
Anelise Schaurich dos Santos \\ Universidade Federal de Santa Maria - Santa Maria - RS \\ Danielle da Costa Souto \\ Universidade Federal de Santa Maria - Santa Maria - RS \\ Katia Simone da Silva Silveira \\ Universidade Federal de Santa Maria - Santa Maria - RS \\ Claudia Maria Perrone \\ Universidade Federal de Santa Maria - Santa Maria - RS \\ Ana Cristina Garcia Dias \\ Universidade Federal do Rio Grande do Sul - Porto Alegre - RS \\ Universidade Federal de Santa Maria - Santa Maria - RS
}

\begin{abstract}
Resumo
Este estudo objetivou refletir sobre o trabalho desenvolvido por psicólogos no contexto das Instituições de Ensino Superior. Parte-se do pressuposto de que as alterações na rotina que advêm do ingresso no ensino superior podem fazer com que acadêmicos apresentem problemas psicológicos. A implementação de serviços dentro das universidades que visam à otimização do bem-estar físico e psicológico dos estudantes busca auxiliar no enfrentamento de tais dificuldades. Os resultados revelam que, tradicionalmente, as intervenções psicológicas realizadas nessas instituições são voltadas ao público discente por meio de atendimentos clínicos individuais. Contudo, atividades provenientes de uma concepção crítica de Psicologia Escolar e Educacional, como aquelas que enfatizam a adaptação acadêmica, o aconselhamento de carreira e o processo ensino-aprendizagem, vêm ganhando ênfase. Também há relatos de práticas voltadas aos docentes e funcionários. Concluiu-se que a atuação dos psicólogos no ensino superior vivencia um processo de transição marcado pela busca de novas formas de atuação.
\end{abstract}

Palavras-chave: Psicologia Escolar; atuação do psicólogo; ambiente universitário.

\section{Psychologist Educational and School performance in higher education: reflections about practice?}

\begin{abstract}
This study aimed to reflect about the work of psychologists in the context of higher education institutions. This is on the assumption that changes in routine that come from access to higher education may cause psychological problems in students. The implementation services within universities aimed to optimizing the physical and psychological well-being of students seeking help in coping with such difficulties. The results show that, traditionally, psychological interventions in these institutions are geared to the public student through individual clinical care. However, activities from a critical conception of School and Educational Psychology, as those that emphasize academic adaptation, career counseling and teachinglearning process, are gaining emphasis. There are also reports of practices geared to teachers and staff. It was concluded that the work of psychologists in higher education experiences a transition marked by the search for new forms of action.
\end{abstract}

Keywords: School Psychology; the psychologist work; university environment.

\section{Actuación del Psicólogo Escolar y Educacional en la enseñanza superior: reflexiones sobre prácticas}

\section{Resumen}

Este estudio tuvo por objetivo reflexionar sobre el trabajo desarrollado por psicólogos en el contexto de las Instituciones de Enseñanza Superior. Se parte del presupuesto de que las alteraciones en la rutina que adviene del ingreso en la enseñanza superior pueden hacer con que académicos presenten problemas psicológicos. La implementación de servicios dentro de las universidades que visan la optimización del bien-estar físico y psicológico de los estudiantes busca auxiliar en el enfrentamiento de tales dificultades. Los resultados enseñan que, tradicionalmente, las 
intervenciones psicológicas realizadas en esas instituciones son volcadas al público discente por medio de atenciones clínicos individuales. Sin embargo, actividades provenientes de una concepción crítica de Psicología Escolar y Educacional, como aquellas que enfatizanla adaptación académica, el asesoramiento de carrera y el proceso enseñanza-aprendizaje, viene ganando énfasis. También hay relatos de prácticas volcadas a los docentes y funcionarios. Se concluye que la actuación de los psicólogos en la enseñanza superior vivencia un proceso de transición marcado por la búsqueda de nuevas formas de actuación.

Palabras clave: Psicología Escolar; actuación del psicólogo; ambiente universitario

\section{Introdução}

O contexto universitário é um importante ambiente para o desenvolvimento dos jovens (Bardagi, \& Hutz, 2012), pois apresenta um impacto em suas trajetórias de vida que vai além da profissionalização (Teixeira, Dias, Wattrich, \& Oliveira., 2008). O ingresso no ensino superior é acompanhado por acontecimentos singulares, como a saída da casa dos pais, a mudança de cidade, o distanciamento do núcleo familiar (Assis, \& Oliveira, 2011; Sulkowski, \& Joyce, 2012), a transformação das amizades e a troca dos professores do ambiente escolar para o acadêmico (Teixeira, \& cols., 2008). Ademais, é marcado por escolhas importantes na trajetória pessoal e profissional dos estudantes (Assis, \& Oliveira, 2011; Ribeiro, \& Bolsoni-Silva, 2010), como o prosseguimento dos estudos ou ingresso no mundo do trabalho, com todas as subescolhas que cada opção acompanha (Soares, 2002).

Diante de novas exigências e mudanças, os universitários podem apresentar psicopatologias, como estresse, depressão, ansiedade e disfunção alimentar (Sulkowski, \& Joyce, 2012). Em alguns casos, os estudantes recorrem ao uso e abuso de drogas lícitas e/ou ilícitas para enfrentar suas dificuldades (Assis, \& Oliveira, 2011). Esses problemas revelam a importância da implementação de serviços, especialmente dentro das Instituições de Ensino Superior (IES), que visam à facilitação da integração do estudante à vida acadêmica e à otimização do seu bem-estar físico e psicológico (Teixeira, Castro, \& Piccolo, 2007).

As atividades desenvolvidas por esses serviços não necessariamente precisam caracterizar-se por atendimentos clínicos individuais (Marinho-Araújo, 2009). Conforme será discutido no decorrer deste estudo, espera-se que os psicólogos que atuam em IES estejam preparados para lidar com demandas grupais, mas saibam identificar a necessidade de desenvolver ações individuais, o que depende da situação vivenciada por cada estudante (Bisinoto, \& Marinho-Araújo, 2011).

Os serviços de atendimento a universitários foram criados com a finalidade de dar assistência social, econômica, física e psicológica aos acadêmicos (Assis, \& Oliveira, 2011). A União Nacional de Estudantes (UNE) descreve a assistência estudantil como o conjunto de políticas que objetivam garantir a redução das desigualdades socioeconômicas e culturais, o combate à evasão e a promoção de uma formação completa, equânime a todos os estudantes (União Nacional de Estudantes [UNE], 2003). A assistência deve proporcionar condições básicas para a permanência do universitário na instituição, assegurar os meios necessários ao pleno desenvolvimento acadêmico e contribuir para a melhoria do sistema universitário (UNE, 2003). Portanto, iniciativas desenvolvidas nas áreas de moradia, de alimentação, de transporte, de assistência à saúde, de inclusão digital, de cultura, de esporte e de apoio pedagógico são ações voltadas para a assistência estudantil (Assis, \& Oliveira, 2011).

Entre os anos de 1999 e 2000, o Fórum de Pró-Reitores de Assuntos Comunitários e Estudantis (FONAPRACE), ligado à Associação Nacional de Reitores das Universidades Federais Brasileiras, realizou um mapeamento sobre as ações de assistência aos estudantes praticadas nas IES do setor público brasileiro. Participaram desse mapeamento representantes de 40 instituições federais e estaduais. Identificou-se que, na área da saúde, as universidades oferecem aos discentes principalmente atendimentos médicos, exames diagnósticos, atendimento odontológico e programas para prevenir e tratar a dependência química. Entretanto, das 40 instituições que participaram do levantamento, apenas $34 \%$ ofereciam algum tipo de atendimento efetivamente voltado à saúde mental dos discentes (Assis, \& Oliveira, 2011).

As práticas de assistência nos serviços de atendimento aos universitários frequentemente são voltadas a ações relacionadas à moradia, à alimentação e ao transporte. Possibilidades como a Casa do Estudante, o Restaurante Universitário, o recebimento de bolsas-auxílio e o pagamento de metade da passagem de ônibus ou isenção dessa taxa são serviços de assistência indispensáveis para a permanência acadêmica e a conclusão da graduação (Barreto, Bezerra, \& Barbosa, 2004).

Contudo, ainda é pequeno o número de universidades nas quais são realizadas ou planejadas ações para o atendimento das necessidades de saúde mental (Assis, \& Oliveira, 2011) ou de ajustamento à vida acadêmica (Teixeira, \& cols., 2007) dos universitários. De fato, a maioria das IES pouco se preocupa com a preparação dos indivíduos para as mudanças que ocorrem após o ensino médio. A oferta de programas que favorecem a adaptação psicossocial dos estudantes é limitada (Ribeiro, \& Bolsoni-Silva, 2011) e a saúde mental não recebe a devida atenção no ensino superior (Assis, \& Oliveira, 2011) apesar do aumento da prevalência e da gravidade de problemas psicológicos entre os universitários (Hyun, Quinn, Madon, \& Lustig, 2006; Sulkowski, \& Joyce, 2012).

Provavelmente o despreparo dos psicólogos para lidar com questões do cotidiano acadêmico de universitários seja decorrente do modelo clínico de formação da maioria dos cursos de psicologia (Vieira, Figueiredo, Souza, \& Fenner, 2013). Esse modelo é fundamentado em uma visão curativa e individualizada dos processos psicológicos (Vieira, \& cols., 2013), que provavelmente ocorre devido à adoção de uma formação centrada em disciplinas que enfatizam o psicodiagnóstico, as psicoterapias e as técnicas de 
exame psicológico na maioria dos cursos de graduação em psicologia (Souza, 2009).

A carência de conhecimentos, por parte dos psicólogos, acarretou a atrofia de áreas de atuação historicamente anteriores à prática clínica, como as áreas organizacionais, institucionais e educacionais (Souza, 2009). Isso tende a fazer com que as atividades desenvolvidas por psicólogos em espaços educacionais sejam simplistas, reducionistas, excludentes e culturalmente descontextualizadas, uma vez que esse profissional não aprende a executar sua prática de outra forma (Vieira, \& cols., 2013). Na verdade, para atuar no contexto educacional, é imprescindível analisar e compreender as relações complexas que são estabelecidas entre a psicologia e a educação (Leal, Facci, Albuquerque, Tuleski, \& Barroco, 2005).

Somado a isso, ainda é comum a existência de uma lacuna entre o que se aprende nos cursos de graduação em psicologia e as demandas apresentadas pelo mercado de trabalho (Vieira, \& cols., 2013). Por essa razão, muitos graduandos em psicologia desconhecem as possibilidades de prática profissional no âmbito educacional (Souza Filho, Oliveira, \& Lima, 2006) e sentem-se perdidos quando são requisitados a atuar em escolas, IES e outras instituições educativas.

A sensação de estar perdido em relação à prática profissional da Psicologia Escolar e Educacional no Brasil parece estar se agravando atualmente. Isso acontece porque os psicólogos vêm se deparando com a expansão e a democratização do acesso a educação superior pública no país, realizado principalmente a partir da década de 90 (Lima, 2013). O aumento das vagas nas universidades públicas faz com que mais jovens ingressem nas universidades (Neves, 2012), o que requer da psicologia ações de apoio que busquem contemplar o maior número possível de acadêmicos.

Mais do que isso, a ampliação das vagas possibilita o ingresso nas universidades de um público que antigamente não tinha acesso ao ensino superior, como negros, indígenas, população desfavorecida economicamente e pessoas com deficiência. Isso é possível por meio das leis número 12.711 (Brasil, 2012) e número 7.853 (Brasil, 1989), sancionadas em 29 de agosto de 2012 e 24 de outubro de 1989, respectivamente.

A primeira lei versa sobre a obrigação das instituições federais de educação superior reservarem no mínimo $50 \%$ de suas vagas (por curso e por turno) para estudantes que tenham cursado integralmente o ensino médio em escolas públicas, sendo $50 \%$ delas destinadas aos alunos provenientes de famílias com renda igual ou inferior a um salário mínimo e meio per capita (Brasil, 2012). Além disso, essas vagas deverão ser preenchidas por autodeclarados pretos, pardos e indígenas em proporção no mínimo igual à de pretos, pardos e indígenas da população do estado brasileiro onde está instalada a instituição (Brasil, 2012). Já a segunda lei dispõe sobre o apoio às pessoas com deficiência e sua integração social, garantindo a oferta obrigatória e gratuita de educação técnica em estabelecimento público de ensino, o que inclui o ensino superior (Brasil, 1989).
A entrada desse público no ensino superior requer que as IES preocupem-se com a permanência dessas pessoas na universidade de maneira que elas possam usufruir de condições adequadas para realizarem e concluírem com boa qualidade os seus estudos (Moehlecke, 2004; Sobrinho, 2010). Acredita-se que esse contexto de expansão da educação superior apresenta um novo campo de atuação para a Psicologia Escolar e Educacional, uma vez que a realidade e as necessidades de negros, indígenas, população desfavorecida economicamente e pessoas com deficiência precisam ser conhecidas e apoiadas.

Destaca-se ainda que as IES privadas também estão passando por um período de expansão (Lima, 2013; Neves, 2012). Do total de 2.377 IES brasileiras, 2.100 são privadas (Instituto Nacional de Estudos e Pesquisas Educacionais Anísio Teixeira/Ministério da Educação [INEP/MEC], 2011). Esse número dobrou em dez anos, uma vez que no ano de 2000 o número de IES privadas era 1.004 (INEP/MEC, 2011). Apesar das IES privadas dominarem o cenário nacional de educação superior, a maioria dos programas de assistência estudantil é criada e executada em universidades estaduais ou federais (Assis, \& Oliveira, 2011). Esse dado é preocupante, visto que os acadêmicos que podem usufruir de apoio social, econômico, físico e psicológico quando este existe são a minoria, pois apenas cerca de $12 \%$ das IES brasileiras pertencem à rede pública de ensino (INEP/MEC, 2011).

Esses dados indicam que os psicólogos devem conceder mais atenção para as vivências acadêmicas de discentes pertencentes a instituições particulares. Muitos desses alunos podem se encontrar, por exemplo, em sofrimento por não conseguirem arcar com as despesas da graduação e sob condições de estresse por ter de conciliar a jornada acadêmica com o trabalho (Almeida, Guisante, Soares, \& Saavedra, 2006). Esses são problemas com os quais discentes que cursam graduação em instituições privadas comumente se deparam (Almeida, \& cols., 2006).

Diante do exposto, percebe-se a importância de conhecer as ações desenvolvidas por psicólogos dentro do ambiente acadêmico, uma vez que isso pode auxiliar na sistematização de práticas psicológicas focadas em universitários por meio da diminuição da escassez de estudos sobre o que fazem os psicólogos no ambiente universitário (Bariani, Buin, Barros, \& Escher, 2004) e na construção de uma prática psicológica crítica e com respaldo científico dentro das IES (Zavadski, 2009). Assim, este estudo objetivou refletir sobre o trabalho desenvolvido por psicólogos no contexto das Instituições de Ensino Superior. Primeiramente, serão realizadas algumas reflexões sobre quais atividades os psicólogos desenvolvem nesse ambiente, uma vez que a sua função não se restringe ao atendimento clínico de discentes. Todavia, é importante conhecer o que esses profissionais realizam para melhorar a experiência universitária dos estudantes e otimizar o desenvolvimento psicológico e social dos alunos. Por essa razão, em seguida serão discutidas quais práticas psicológicas são frequentemente realizadas nos serviços de assistência estudantil. 


\section{Funções e papéis do Psicólogo Escolar e Educacional nas Instituições de Ensino Superior}

Antes de iniciar as discussões sobre este tópico, acredita-se ser importante explicar por quais motivos o psicólogo que atua em IES será nomeado Psicólogo Escolar e Educacional neste trabalho. Historicamente, a Psicologia Escolar e a Psicologia Educacional permaneceram como campos distintos até recentemente (Souza, 2009). Contudo, assim como Dias, Patias e Abaid (2014) e Souza (2009), as autoras desta revisão acreditam que não há como separar esses termos, uma vez que se complementam e estão intrinsecamente ligados, apesar de não serem idênticos (Antunes, 2008).

O termo Psicólogo Educacional deriva da nomenclatura Psicologia Educacional, que é considerada uma subárea de conhecimento em psicologia (Antunes, 2008). Essa subárea se ocupa da teorização e produção de saberes sobre a relação entre a psicologia e o processo educativo (Barbosa, \& Souza, 2012). Ou seja, é uma área de pesquisa em psicologia (Souza, 2009). Já o termo Psicólogo Escolar é derivado da Psicologia Escolar, que corresponde a um âmbito profissional e a um campo de ação determinado desse profissional (Antunes, 2008). A Psicologia Escolar se refere à atuação ou prática do psicólogo em contextos educativos diversos (Barbosa, \& Souza, 2012; Souza, 2009). Essa dicotomia começou a ser questionada a partir dos anos de 1980 por uma perspectiva crítica que considera que teoria e prática são elementos indissociáveis na constituição de uma ciência humana (Souza, 2009). Visto que o psicólogo atuante em IES é tanto produtor de conhecimentos (Psicólogo Educacional) quanto executor de uma prática psicológica em um ambiente educativo (Psicólogo Escolar), ele será chamado de Psicólogo Escolar e Educacional.

A carência de formação para psicólogos que pretendem atuar no âmbito universitário conduz a uma reflexão sobre a qualificação do profissional que trabalha junto ao público das universidades. Frquentemente o psicólogo é chamado a atuar quando algum problema já se instalou; porém, no caso de universitários, é necessário que a assistência psicológica seja abrangente e inserida em diversos contextos da vida acadêmica e social (Sampaio, 2010) de maneira a ajudar os estudantes a construírem um processo educacional qualitativamente superior (Leal, \& cols., 2005). Para isso, é necessário que o Psicólogo Escolar e Educacional passe a se preocupar menos com a resolução de problemas e mais em não permitir que estes se instalem. Assim, é sua função auxiliar a instituição a refletir e a implementar ações que minimizem os obstáculos que se colocam entre os sujeitos e o conhecimento, possibilitando o desenvolvimento do pensamento crítico e favorecendo processos de humanização (Leal, \& cols., 2005).

Também é importante que o psicólogo que atua em IES desenvolva algum vínculo e manejo com os docentes e gestores. Observa-se que esse profissional ainda desconhece a articulação entre as esferas responsáveis por decisões das políticas universitárias, embora exista integração entre ele e o ambiente da educação superior. Geralmente o profissional da psicologia fica alheio às discussões que envolvem a relação entre a comunidade e a universidade, as quais possibilitam a criação de ações inovadoras no ambiente acadêmico (Sampaio, 2010). Espera-se que o psicólogo que atua em IES perceba a Psicologia Escolar e Educacional em uma vertente crítica desta área do conhecimento ao entendê-la como um campo de estudos, de atuação e de formação do psicólogo que busca compreender o fenômeno educacional como produto das relações que se estabelecem no interior das instituições de ensino (Souza, 2009).

Tradicionalmente, as atividades desenvolvidas por psicólogos na universidade são: o acompanhamento individual, a realização de encaminhamentos externos e internos e o desenvolvimento de orientações em grupos, sendo a maioria com foco nos discentes (Serpa, \& Santos, 2001). Destaca-se que para a realização de encaminhamentos dos acadêmicos, é essencial que as Clínicas-Escola de psicologia e os serviços de saúde estejam preparados para compreender e lidar com problemas psicológicos relacionados ao contexto universitário, uma vez que os estudantes podem apresentar demandas de tratamento diferentes de outros grupos, pois é comum que no início da vida adulta, em que geralmente acontece o ingresso na universidade, ocorra o surgimento de transtornos mentais (Neves, \& Dalgalarrondo, 2007). Os universitários tendem a ser acometidos por distúrbios não psicóticos, isto é, transtornos mentais menores, os quais englobam sintomas ansiosos, depressivos e somáticos (Carneiro, \& Baptista, 2012; Cerchiari, Caetano, \& Faccenda, 2005; Neves \& Dalgalarrondo, 2007). Por isso, é dever dos Psicólogos Escolares e Educacionais se preocuparem com a articulação de ações no plano da formação profissional com as Clínicas-Escola para o atendimento de queixas educacionais e entre os psicólogos que atuam na área da educação com os que se encontram na área da saúde, ampliando a compreensão do processo educação formal e sua importância na constituição dos indivíduos (Souza, 2009).

O trabalho dos psicólogos das IES ainda pode envolver a avaliação da instituição e dos professores e o aperfeiçoamento da prática docente por meio do planejamento e desenvolvimento de metodologias diferenciadas. Nesse caso, o psicólogo pode acompanhar as práticas educativas dos docentes e a aprendizagem dos alunos, a fim de sugerir alternativas ou construir em conjunto programas inovadores de ensino, que auxiliem os professores a melhorar suas habilidades profissionais e favorecer o aprendizado dos discentes. Assim, privilegia-se uma atuação menos vinculada ao aspecto individualista de atenção ao estudante e mais atrelada a uma compreensão sistêmica do processo de ensino e às vivências acadêmicas do ensino superior (Bisinoto, \& Marinho-Araújo, 2011).

Em âmbito institucional, a psicologia pode atuar na educação superior (1) na gestão de políticas, programas e processos educacionais das IES, (2) na elaboração de propostas pedagógicas e no funcionamento de cursos e (3) no auxílio psicológico a estudantes. Sobre a primeira dimensão, acredita-se que esse profissional pode assessorar ações 
ligadas à gestão institucional, acompanhar o processo de autoavaliação institucional, contribuir para a ambientação de novos colaboradores e assessorar a definição e reformulação dos perfis docentes e técnicos. Na segunda dimensão, pretende-se que o psicólogo apóie o desenvolvimento de competências discentes e acompanhe o processo de ensino-aprendizagem. Já na terceira dimensão, indica-se que o psicólogo trabalhe com os universitários. Isso é possível por meio da promoção de estratégias de desenvolvimento acadêmico e social dos estudantes (Marinho-Araújo, 2009).

Percebe-se que a prática da Psicologia Escolar e Educacional na educação superior desenvolve-se com base em diversos modelos, os quais podem ser organizados em dois grupos. De um lado, existem intervenções que são essencialmente centradas nos estudantes, as quais podem ser executadas em diferentes níveis, a saber, remediativo, preventivo e de promoção do desenvolvimento. De outro lado, encontram-se propostas mais abrangentes, desenvolvidas com toda a comunidade acadêmica, ou seja, alunos, professores e funcionários. Tais ações são desempenhadas junto a instâncias institucionais menos tradicionais, como propostas pedagógicas, assessoria ao trabalho docente, formação continuada de professores e funcionários, e autoavaliação institucional (Bisinoto, Marinho-Araújo, \& Almeida, 2010).

A atuação dos Psicólogos Escolares e Educacionais na educação superior vivencia um processo de transição marcado pela revisão de práticas consolidadas e pela integração de outras diferenciadas (Bisinoto, \& Marinho-Araújo, 2011), uma vez que o conhecimento psicológico no campo da educação precisa ser constantemente construído, revisitado, criticado e superado (Souza, 2009). Atualmente, a Psicologia Escolar e Educacional possui o desafio de não desconsiderar aspectos contextuais, institucionais, políticos, éticos, sociais, econômicos e interacionais que interferem nas vivências acadêmicas dos discentes (Bisinoto, \& Marinho-Araújo, 2011) e não desvincular a sua prática da relação entre "psicologia-educação-sociedade" (Leal, \& cols., 2005, p. 95). Assim, busca-se construir uma atuação mais ampliada no que se refere à compreensão dos fatores envolvidos no cotidiano escolar e aos participantes (alunos, professores e funcionários) que o produzem (Bisinoto, \& Marinho-Araújo, 2011).

Todavia, a ênfase sobre o aluno ainda é bastante frequente na Psicologia Escolar e Educacional (Bisinoto, \& Marinho-Araújo, 2011). Isso não significa que as ações desenvolvidas pelo psicólogo que atua nesse campo devem seguir a atividade clínica tradicional, caracterizada pelo exame das manifestações da doença para fazer um diagnóstico, um prognóstico e descrever um tratamento, conforme a origem da clínica psicológica remontada ao fazer médico (Moreira, Romagnoli, \& Neves, 2007). Espera-se que a percepção clínica dos psicólogos que atuam em IES não seja sinônimo de atendimentos clínicos individuais, mas sim de manejos que previnam a necessidade destes e/ou que visem à promoção da saúde (Lo Bianco, Bastos, Nunes, \& Silva, 1994). Acredita-se que esse é o modelo clínico no qual os psicólogos devem pautar sua prática independente do seu âmbito de atuação. Tal modelo precisa evitar abstrair o ser humano do contexto em que ele vive de forma a pensar o sujeito como aquele que constitui e é constituído no mundo (Dutra, 2004). Assim, o modelo clínico, o qual se indica que seja seguido pelos Psicólogos Escolares e Educacionais, refere-se ao espaço de escuta do não dito, independente do local em que aconteça, seja no âmbito privado ou público, em uma relação diádica, grupal ou coletiva (Dutra, 2004). Ao levar em consideração esse modelo, a seção seguinte dedica-se a entender as diversas formas de atuação do psicólogo no atendimento aos estudantes universitários.

\section{Atendimentos prestados por psicólogos aos estudantes universitários}

A otimização do bem-estar psicossocial dos discentes demanda a atuação de psicólogos no âmbito da educação superior, uma vez que esse profissional pode contribuir para a prevenção e solução de problemas presentes no cotidiano acadêmico (Bisinoto, \& Marinho-Araújo, 2011). A ausência de psicólogos que trabalhem em programas de apoio ao estudante contribui para a permanência de uma série de dificuldades frequentemente enfrentadas por universitários, como formação básica insuficiente ou inadequada, falta de habilidades de leitura, escrita e estudo e insegurança na tomada de decisões (Serpa, \& Santos, 2001).

Os psicólogos que atuam em IES podem ajudar a qualificar os processos de ensino-aprendizagem e a apropriação do conhecimento científico pelos alunos (Zavadski, 2009). Além disso, psicólogos que atuam no ensino superior tendem a contribuir para resolução de problemas de ordem pessoal, os quais, muitas vezes, surgem em decorrência do ingresso no ensino superior e acabam por afetar a vida acadêmica dos discentes (Peres, Santos, \& Coelho, 2003).

Frequentemente, os serviços de atendimento psicológico aos estudantes de IES possuem os objetivos de atender às dificuldades vivenciadas por universitários, apoiar o desenvolvimento acadêmico e promover o desenvolvimento integral dos alunos. Ao tomar como base esses propósitos, algumas atividades são realizadas para contemplar as demandas dos discentes. Dentre elas, pode-se citar os atendimentos psicológico, pedagógico e psicopedagógico, o apoio ao processo de ensino-aprendizagem e o auxílio na gestão da carreira, encaminhamento profissional e a reorientação profissional. Além disso, em algumas IES, os psicólogos também são responsáveis por orientar pessoas com deficiências, acolher calouros e atender egressos (Bisinoto, \& Marinho-Araújo, 2011).

As atividades acima elencadas são divididas em tradicionais e emergentes. As atividades tradicionais englobam, por exemplo, os atendimentos e os processos de orientação profissional, uma vez que são ações consolidadas na área de Psicologia Escolar e Educacional no ensino superior. Já as atividades emergentes são mais recentes, abrangentes e complexas do que as tradicionais. Elas compreendem, por exemplo, o apoio ao processo de ensino-aprendizagem, a 
orientação a pessoas com deficiências, o acolhimento a calouros e o atendimento a egressos. Destaca-se que ambos os tipos de possibilidades interventivas já fazem parte do cotidiano de atuações dos psicólogos no ensino superior, apesar de as atividades tradicionais prevalecerem em relação às emergentes, já que respondem por $52 \%$ das ações do profissional (Bisinoto, \& Marinho-Araújo, 2011).

A respeito de uma intervenção tradicional, pode-se citar o estudo realizado para descrever o serviço de atendimento psicológico oferecido junto à clínica-escola da Faculdade de Ciências e Letras de Assis da Universidade Estadual Paulista (UNESP), voltado exclusivamente à comunidade discente interna. Os estudantes atendidos pelo serviço buscavam atendimento psicoterápico individual devido a problemas de convívio com companheiros de moradia, aumento nos níveis de ansiedade e estresse em virtude das atividades acadêmicas, resistência para se desligarem ou se distanciarem das pessoas com as quais mantinham um relacionamento íntimo na cidade de origem e dificuldades para se adaptarem à nova cidade, incluindo o estabelecimento de vínculos afetivos na nova cidade. Esse estudo demonstra a importância da criação de serviços de atendimento psicológico voltados especificamente a estudantes universitários, visto que representam uma modalidade de intervenção relevante e ainda pouco explorada na realidade brasileira (Peres, \& cols., 2003).

Destaca-se que ações como a mencionada anteriormente, as quais visam à otimização do bem-estar dos discentes, tendem a privilegiar o acompanhamento e atendimento imediato a problemas vivenciados pelos estudantes em uma perspectiva de intervenção breve. Nesse caso, fatores como a estrutura curricular, as estratégias de ensino e de avaliação e a qualidade das relações no espaço universitário, os quais também interferem na promoção da saúde em âmbito acadêmico, raramente têm sido alvo de intervenções da psicologia em IES no Brasil (Bisinoto et al., 2010).

Sabe-se também que poucas instituições brasileiras preocupam-se com a realização de programas de adaptação acadêmica, como ocorre, por exemplo, nos Estados Unidos (Mattanah, \& cols., 2010). Há indícios de que nas IES brasileiras os serviços orientados à adaptação acadêmica e ao sucesso escolar dos estudantes englobam majoritariamente a realização de workshops de desenvolvimento pessoal e de competências acadêmicas, de gestão do tempo e de ansiedade (Dias, 2001).

Já nas universidades norte-americanas esses programas contemplam sessões estruturadas para a concessão de informações sobre a universidade, além de intervenções clínicas, no caso de estudantes que apresentam grande dificuldade para se ajustar ao contexto do ensino superior. Ademais, é comum a realização de grupos de apoio para calouros nessas instituições, a fim de discutir sobre a vida no ensino superior. Geralmente, esses grupos iniciam-se na primeira semana de ingresso na universidade e são compostos de seis a dez encontros. Os resultados indicam que os acadêmicos que participaram de tais encontros perceberam maiores níveis de apoio social, essencial para a adaptação ao ambiente universitário, e apresentaram níveis mais baixos de solidão e depressão (Mattanah, \& cols., 2010).

Em alguns casos, os psicólogos que atuam nas IES se dedicam ao aconselhamento de carreira dos estudantes e preparação dos mesmos para o mercado de trabalho. 0 modelo de aconselhamento de carreira proposto pelo Serviço de Aconselhamento e Gestão de Carreira para Promoção da Empregabilidade da Universidade de Lisboa, em Portugal, procura ajudar o indivíduo a compreender as suas próprias necessidades, a definir os seus objetivos e a gerir a sua carreira (Lima, \& Fraga, 2010). Ao analisar o tipo de ajuda solicitada nesse serviço por estudantes que frequentavam desde o primeiro até o último ano de vários cursos do ensino superior, é possível caracterizar os estudantes segundo três tipos de solicitação, a saber, mudança de curso, clarificação de objetivos e especificação da formação (Lima, \& Fraga, 2010).

No Brasil, os serviços de planejamento de carreira oferecidos para universitário possuem características diferenciadas em relação ao atendimento individual e/ou em grupo. Os enfoques são na opção por outro curso, preparação para busca de estágios, programas de trainee e emprego (Knabem, 2013). São objetivos dos processos de planejamento de carreira: abrir um espaço para reflexão dos alunos sobre valores, metas e projetos pessoais e profissionais futuros, promover o autoconhecimento e a ampliação do conhecimento sobre as diferentes possibilidades de atuação profissional e instrumentalizar os alunos para participação em processos seletivos, busca de emprego, participação em entrevistas e elaboração de currículo. A fim de atingir tais objetivos, o mais frequente é a realização de oficinas e palestras de sensibilização sobre carreira e transição universidade-mercado de trabalho (Bardagi, 2013).

Para exemplificar tais ações, destaca-se a criação do Projecta, programa de orientação de carreira que integra o Serviço de Apoio ao Estudante da Universidade Estadual de Campinas (Unicamp), localizada no estado de São Paulo (Brissac, Domingues, Pelissoni, \& Freitas, 2013). As ações do Projecta são grupais, realizadas por psicólogos e destinadas a graduandos e pós-graduandos da Unicamp. O programa foi estruturado em módulos, os quais são denominados "De bem com meu curso: refletindo sobre a escolha!", "O próximo passo, saindo da universidade", "O currículo como porta de entrada para o mundo do trabalho", "Vivência e sucesso em entrevistas de seleção" e "Dinâmica de grupo: a experiência de um processo de seleção". Os resultados das avaliações quantitativas e qualitativas evidenciaram a importância desse espaço na universidade e a eficácia desse formato de intervenção (Brissac, \& cols., 2013).

Percebe-se que a intervenção psicológica em orientação e desenvolvimento de carreira com estudantes do ensino superior influencia e ajuda os indivíduos a responderem às questões que se colocam ao longo de seus percursos de vida. Isso é possível a partir do fomento ao autoconhecimento e ao autodesenvolvimento, além da antecipação de cenários de vida face às mudanças que ocorrem e que se refletem nos diferentes papéis que os estudantes desempenham (Lima, \& Fraga, 2010). 
Ainda como exemplo da atuação do psicólogo junto ao estudante universitário pode-se citar o trabalho desenvolvido na Universidade do Minho, em Portugal, a qual integra o Serviço de Consulta Psicológica e Desenvolvimento Humano (SCPDH). O apoio psicológico aos alunos proporciona atendimentos clínicos de aconselhamento psicológico, de desenvolvimento educacional e vocacional, a fim de facilitar a resolução de problemas e melhorar o desenvolvimento pessoal dos alunos que se deparam com a experiência universitária (Rede de Serviços de Aconselhamento Psicológico no Ensino Superior [RESAPES], 2002).

Outra universidade que se destaca em razão do serviço prestado ao estudante universitário é a Universidade de Porto, também em Portugal. A Área de Apoio Psicológico (APP) dessa universidade entende que as vivências acadêmicas são experiências significativas, as quais podem criar oportunidades para reorganizações pessoais e ocasionar o aparecimento de sentimentos de sucesso ou fracasso e, comumente, de insegurança para o universitário. O foco desse serviço é a oferta de um conjunto de propostas de formação dirigidas aos universitários. As atividades estão organizadas de forma temática - competências de empregabilidade, métodos e técnicas de estudo, comunicação e contextos de trabalho - e ganham gradativamente maior consistência e adesão por parte dos acadêmicos. Dessa forma, o desenvolvimento pessoal e social deixou de estar exclusivamente focalizado nas situações de crise para evidenciar os momentos de formação extracurricular. Assim, as principais atividades desenvolvidas junto ao estudante universitário são: o aconselhamento, as consultas psicológicas e os grupos de formação (RESAPES, 2002).

Nesta seção pretendeu-se apresentar aspectos que contemplassem o trabalho desenvolvido pelo psicólogo com os estudantes universitários dentro de algumas IES nacionais e internacionais. Foram apresentados principalmente os casos de universidades portuguesas e norte-americanas, pois essas são as principais influências sofridas pelos Psicólogos Escolares e Educacionais brasileiros. Ademais, as pesquisas sobre universitários e as intervenções psicológicas destinadas a esse público são consolidadas nesses países. Percebeu-se que a inserção do Psicólogo Escolar e Educacional no contexto universitário é recente. Por essa razão, os atendimentos realizados nesses locais configuram-se, predominantemente, como a intervenção tradicional, ou seja, o atendimento clínico individual. Contudo, em alguns locais, são realizadas ações mais abrangentes, as quais apoiam os discentes para o desenvolvimento de diversas habilidades, como a adaptação ao contexto do ensino superior e o planejamento de suas carreiras.

\section{Considerações finais}

O objetivo deste estudo foi refletir sobre o trabalho desenvolvido por psicólogos no contexto das Instituições de Ensino Superior. Identificou-se que o conhecimento sobre a atuação do psicólogo nas IES ainda é restrito. Os poucos estudos encontrados permitiram constatar que, tradicionalmente, o psicólogo foca sua prática em ações voltadas aos discentes. Nesse caso, a atividade mais comum são os atendimentos clínicos individuais em uma perspectiva breve, os quais visam solucionar problemas psicológicos frequentemente desencadeados pelo ingresso no ensino superior.

Contudo, a atuação dos Psicólogos Escolares e Educacionais na educação superior vivencia um processo de transição marcado pela revisão de práticas consolidadas e pela integração de outras diferenciadas. Assim, o profissional da psicologia tem inserido ações voltadas à adaptação acadêmica, ao aconselhamento de carreira e a qualificação do processo ensino-aprendizagem dos estudantes em seu conjunto de possíveis atuações. Também há maior ênfase em práticas a serem executadas com docentes e funcionários, como contribuir para a ambientação de novos colaboradores, assessorar a definição e formulação dos perfis docentes e técnicos, e apoiar o desenvolvimento de competências discentes. Diante dessas práticas, percebe-se uma visão crítica da Psicologia Escolar e Educacional nas IES, a qual compreende o fenômeno educacional como produto das relações que se estabelecem no interior das instituições de ensino.

Notou-se também que dificilmente as ações de assistência estudantil relatadas pelos estudos são executadas no âmbito do ensino superior privado. Isso pode ocorrer porque, provavelmente, nas IES particulares não há a contratação de profissionais que se ocupem exclusivamente em pensar e realizar programas que visem o bem-estar dos acadêmicos. Entretanto, é provável que as ações de assistência estudantil das IES privadas ainda não tenham sido pesquisadas e, por consequência, relatadas, uma vez que a execução de pesquisas com esse viés é mais comum em universidades públicas. Portanto, acredita-se ser importante conhecer quais programas de apoio aos discentes de ensino superior têm sido efetivados no âmbito da educação superior privada, o que pode ser sistematizado por meio de pesquisas em IES particulares.

Acredita-se que a principal contribuição deste estudo é o fato de ele organizar o que já é conhecido sobre a atuação de Psicólogos Escolares e Educacionais em IES e, por meio disso, quais intervenções são comumente realizadas com discentes. É possível que ele minimize uma lacuna teórica existente nos trabalhos sobre atuação do psicólogo, já que esses dificilmente se atentam para o desempenho desse profissional no universo acadêmico. Todavia, este trabalho possui a limitação de apenas descrever quais práticas são desenvolvidas pelos psicólogos em universidades e não aprofundar como e por quais motivos tais ações são executadas. Isso ocorreu porque a maioria dos estudos que embasou esta revisão de literatura tinha como objetivo mapear as atividades desenvolvidas por psicólogos e não explicar os procedimentos de realização das mesmas. Assim, sugere-se a realização de pesquisas empíricas sobre a atuação de psicólogos no contexto do ensino superior, a fim de que as práticas possam ser replicadas e as atividades desempenhadas por esses profissionais consolidem-se nesse campo de atuação. 


\section{Referências}

Almeida, L. S., Guisante, M. A., Soares, A. P., \& Saavedra, L. (2006). Acesso e sucesso no ensino superior em Portugal: questões de género, origem sócio-cultural e percurso acadêmico dos alunos. Psicologia: Reflexão e Crítica, 19(3), 507-514.

Antunes, M. A. M. (2008). Psicologia Escolar e Educacional: história, compromissos e perspectivas. Psicologia Escolar e Educacional, 12(2), 469-475.

Assis, A. D., \& Oliveira, A. G. B. (2011). Vida universitária e saúde mental: atendimento às demandas de saúde e saúde mental de estudantes de uma universidade brasileira. Cadernos Brasileiros de Saúde Mental, 2(4-5), 159-177.

Barbosa, D. R., \& Souza, M. P. R. (2012). Psicologia Educacional ou Escolar? Eis a questão. Psicologia Escolar e Educacional, 16(1), 163-173.

Bardagi, M. P. (2013). Planejamento de carreira com graduandos finalistas: Modelos de intervenções implementadas na UFSC. Anais do Simpósio de Orientação Vocacional e Ocupacional, 11, 101-102.

Bardagi, M. P., \& Hutz, C. S. (2012). Rotina acadêmica e relação com colegas e professores: impacto na evasão universitária. Psico, 43(2), 174-184.

Bariani, I. C. D., Buin, E., Barros, R. C., \& Escher, C. A (2004). Psicologia Escolar e Educacional no ensino superior: análise da produção científica. Psicologia Escolar e Educacional, 8(1), 17-27.

Barreto, I. S., Bezerra, A. L. Q., \& Barbosa, M. A (2005). Assistência universitária - compromisso social. Revista da Universidade Federal de Goiás, 7(2).

Bisinoto, C., \& Marinho-Araújo, C. M. (2011). Psicologia escolar na educação superior: atuação no distrito federal. Psicologia em Estudo, 16(1), 111-122.

Bisinoto, C., \& Marinho-Araújo, C. M., \& Almeida, L. (2010). Contribuições da psicologia escolar à promoção do sucesso acadêmicona educação superior. Anais do ISeminário Internacional "Contributos da Psicologia em Contextos Educativos", 102-116.

Brasil (1989). Lei n 7.853, de 24 de outubro de 1989.

Brasil (2012). Lei no 12.711, de 29 de agosto de 2012.

Brissac, R. M. S., Domingues, C. A. P., Pelissoni, A. M. S., \& Freitas, J. V. (2013). Da necessidade à viabilização de um programa de orientação de carreira no ensino superior: a experiência do Projecta (SAE - Unicamp). Anais do Simpósio de Orientação Vocacional e Ocupacional, 11, 102-103.

Carneiro, A. M., \& Baptista, M. N. (2012). Saúde geral e sintomas depressivos em universitários. Salud \& Sociedad, 3(2), 166-178.

Cerchiari, E. A. N., Caetano, D., \& Faccenda, O. (2005). Prevalência de transtornos mentais menores em estudantes universitários. Estudos de Psicologia, 10(3), 413-420.

Dias, A. C. G., Patias, N. D., \& Abaid, J. L. W. (2014). Psicologia Escolar e possibilidades na atuação do psicólogo: Algumas reflexões. Psicologia Escolar e Educacional, 18(1), 105-111.

Dias, G. F. (2001). Serviços de aconselhamento psicológico no Ensino Superior: uma encruzilhada de questões. Cadernos de Consulta Psicológica, 17-18, 59-67.

Dutra, E. (2004). Considerações sobre as significações da psicologia clínica na contemporaneidade. Estudos de Psicologia, 9(2), 381387.

Hyun, J. K., Quinn, B. C., Madon, T., \& Lustig, S. (2006). Graduate Student Mental Health: Needs Assessment and Utilization of Counseling Services. Journal of College Student Development, 47(3), 247-266.

Instituto Nacional de Estudos e Pesquisas Educacionais Anísio Teixeira/Ministério da Educação [INEP/MEC] (2011). Censo da Educação Superior. Brasília: INEP/Ministério da Educação. Recuperado: 24 abr. 2014. Disponível: http://www.inep.gov.br/ superior/censosuperior.

Knabem, A. (2013). Orientação profissional e de carreira: um levantamento de projetos e ações nas universidades brasileiras. Anais do Simpósio de Orientação Vocacional e Ocupacional, 11, 101.

Leal, L. D., Facci, M. G. D., Albuquerque, R. A., Tuleski, S. C., \& Barroco, S. M. S. (2005). A clínica-escola e o estágio em psicologia na área educacional: fundamentos teóricos e prática profissional. Psicologia da Educação, 21, 79-102.

Lima, P. G. (2013). Políticas de educação superior no Brasil na primeira década do século XXI: alguns cenários e leituras. Avaliação, 18(1), 85-105.

Lima, R., \& Fraga, S. (2010). Intervir para ajudar e ajudar para construir: um modelo de intervenção psicológica com estudantes do ensino superior. Revista Brasileira de Orientação Profissional, 11(2), 269-277.

Lo Bianco, A. C., Bastos, A. V. B., Nunes, M. L. T., \& Silva, R. C. (1994). Concepções e atividades emergentes na psicologia clínica: implicações para a formação. Em Conselho Federal de Psicologia (Org.), Psicólogo brasileiro: práticas emergentes e desafios para a formação (pp. 7-76). São Paulo: Casa do Psicólogo.

Marinho-Araújo, M. C. (2009). Psicologia Escolar na Educação Superior: novos cenários de intervenção e pesquisa. Em C. M. Marinho-Araújo (Org.), Psicologia Escolar: novos cenários 
e contextos de pesquisa, formação e prática (pp. 155-202). Campinas: Alínea.

Mattanah, J. F., Ayers, J. F., Brand, L. B., Brooks, L. J., Quimby, J. L., \& Scot, M. W. (2010). A Social Support Intervention to Ease the College Transition: Exploring Main Effects and Moderators. Journal of College Student Development, 51(1), 93-108.

Moehlecke, S. (2004). Ação afirmativa no ensino superior: entre a excelência e a justiça racial. Educação \& Sociedade, 25(88), 757776.

Moreira, J. O., Romagnoli, R. C., \& Neves, E. O. (2007). O surgimento da clínica psicológica: da prática curativa aos dispositivos de promoção da saúde. Psicologia: Ciência e Profissão, 27(4), 608621.

Neves, C. E. B. (2012). Ensino Superior no Brasil: expansão, diversificação e inclusão. Anais do Congresso da Associação de Estudos Latino Americanos, 1-18.

Neves, M. C. C., \& Dalgalarrondo, P. (2007). Transtornos mentais auto-referidos em estudantes universitários. Jornal Brasileiro de Psiquiatria, 56(4), 237-244.

Peres, R. S., Santos, M. A., \& Coelho, H. M. B. (2003). Atendimento psicológico a estudantes universitários: considerações acerca de uma experiência em clínica-escola. Estudos de Psicologia, 20(3), 47-57.

Rede de Serviços de Aconselhamento Psicológico no Ensino Superior [RESAPES]. (2002). A situação dos serviços de aconselhamento psicológico no ensino superior em Portugal, ano de 2002. Serviço de aconselhamento psicológico em Portugal, 2. Recuperado de http://resapes.fct.unl.pt/volume/volume_2.pdf em março de 2014.

Ribeiro, D. C., \& Bolsoni-Silva, A. T. (2010). Potencialidades e dificuldades interpessoais de universitários: estudo de caracterização. Acta Comportamentalia, 19(2), 205-224.

Sampaio, S. M. R. (2010). A psicologia na educação superior: ausências e percalços. Em Aberto, 23, 95-105.

Serpa, M. N. F., \& Santos, A. A. A. (2001). Atuação no ensino superior: um novo campo para o psicólogo escolar. Psicologia Escolar e Educacional, 5(1), 27-35.
Soares, D. H. P. (2002). A escolha profissional do jovem ao adulto. São Paulo: Summus.

Sobrinho, J. D. (2010). Democratização, qualidade e crise da educação superior: faces da exclusão e limites da inclusão. Educação \& Sociedade, 31(113), 1223-1245.

Souza Filho, M., Oliveira, J. S. C., \& Lima, F. L. A. (2006). Como as pessoas percebem o psicólogo: um estudo exploratório. Paidéia, 16(34), 253-261.

Souza, M. P. R. (2009). Psicologia Escolar e Educacional em busca de novas perspectivas. Psicologia Escolar e Educacional, 13(1), 179-182.

Sulkowski, M. L. \& Joyce, D. J. (2012). School psychology goes to college: the emerging role of school psychology in college communities. Psychology in the Schools, 49(8), 809-815.

Teixeira, M. A. P., Castro, G. D., \& Piccolo, L. R. (2007). Adaptação à universidade em estudantes universitários: um estudo correlacional. Interação em Psicologia, 11(2), 211-220.

Teixeira, M. A. P., Dias, A. C. G., Wottrich, S. H., \& Oliveira, A. M. (2008). Adaptação à universidade em jovens calouros. Psicologia Escolar e Educacional, 12(1), 185-202.

União Nacional de Estudantes [UNE] (2003). Reforma Universitária com democracia e por soberania.

Vieira, R. C., Figueiredo, E. R. F., Souza, L. G., \& Fenner, M. C. (2013). A Psicologia da Educação nos cursos de graduação em Psicologia de Belo Horizonte/MG. Psicologia Escolar e Educacional, 17(2), 239-248.

Zavadski, K. C. (2009). A atuação do psicólogo na formação do professor universitário: contribuições da psicologia históricocultural. Dissertação de mestrado, Programa de Pós-Graduação em Psicologia da Universidade Estadual de Maringá, Paraná. 


\section{Sobre as autoras}

Anelise Schaurich dos Santos (anelise_ssantos@hotmail.com)

Mestranda do Programa de Pós-Graduação em Psicologia da Universidade Federal de Santa Maria (PPGP/UFSM), bolsista CAPES/DS.

Danielle da Costa Souto (daniellessouto@hotmail.com)

Mestranda do Programa de Pós-Graduação em Psicologia da Universidade Federal de Santa Maria (PPGP/UFSM), bolsista CAPES/DS.

Katia Simone da Silva Silveira (ksmhd@hotmail.com)

Mestranda do Programa de Pós-Graduação em Psicologia da Universidade Federal de Santa Maria (PPGP/UFSM), bolsista CAPES/DS.

Claudia Maria Perrone (cmperrone@ig.com.br)

Doutora em Psicologia pela Pontifícia Universidade Católica do Rio Grande do Sul (PUCRS). Professora do Departamento de Psicologia da Universidade Federal de Santa Maria (UFSM).

Ana Cristina Garcia Dias (anacristinagarciadias@gmail.com)

Doutora em Psicologia pela Universidade de São Paulo (USP). Professora do Instituto de Psicologia da Universidade Federal do Rio Grande do Sul (UFRGS) e professora colaboradora do Programa de Pós-Graduação em Psicologia da Universidade Federal de Santa Maria (PPGP/UFSM). 